\title{
A Note from the Forum of Federations
}

The current volume Public Security in Federal Polities is part of the Forum of Federations' ongoing commitment to shaping comparative research on federalism. It follows the Forum's work on structural issues of federalism published as a seven-volume set as part of the Global Dialogue Program, as well as multi-country studies on capital cities, oil and gas, internal trade, metropolitan regions, political parties and intergovernmental relations, courts, education, and health care.

In several of the Forum's partner countries, the rise of transnational crime and terrorism has challenged existing security and enforcement arrangements. Federal countries have a plethora of agencies and institutions at different levels of government tasked with enforcement and security functions. Typically, federal governments have the following types of agencies:

1 Armed Forces

2 National or Federal Enforcement Agencies - Customs, Coast Guard, Federal Police

3 Security and Intelligence services

4 Criminal Investigation agencies

5 Militia and paramilitary forces

Provincial and municipal governments are likely to have at their disposal their own:

1 Civilian Police Services

2 Special police or Militia 
While these organizations were established with specific mandates in mind, assignment of responsibilities is not quite as clear-cut as envisaged. Overlapping mandates, mission creep, and different institutional cultures often lead to inter-service competition rather than cooperation. This in turn creates operational problems and hinders effective public security management.

The rise of drug crime and terrorism underscores the need for closer coordination between agencies and across orders of government. As a result the ever-expanding domestic security agenda has shown that no level of government or no one agency is equipped to confront these challenges on its own. Furthermore, except for federal police and investigative agencies specially established for the prosecution of federal crime (United States, Australia), or as institutions for intergovernmental coordination (Germany), federal security and intelligence agencies are traditionally oriented towards confronting external threats (including customs). Given the international dimension to both drug crime and terrorism, federal or central agencies are increasingly being called on to take up domestic security and enforcement mandates - such as calling out the Armed Forces to deal with drug crime or gang violence.

Clearly there are some functions that the federal level is better equipped to perform, whereas others are better left for local entities. Without innovative modes of intergovernmental and interdepartmental cooperation federal agencies risk dissipating federal governments' energies, while eroding the value added and flexibility contributed by local entities.

The challenge becomes particularly acute when communities encounter security challenges that transcend the community's ability to cope internally, that is, which require outside assistance. A possible point of friction is that outsiders may not share the community's values and thus misunderstand the community's security needs, but they may also end up being perceived as a threat. The source of such challenges at the community level may be a genuine security problem. However, it may also be a function of inadequate funding and/or intelligence sharing and/or inter-agency cooperation by higher levels of government, thus putting subnational and/or municipal forces in the sort of quandary which conjures up a security problem that subsequently provides the rationale for federal intervention. So, we want to identify not only the nature of the security challenges but also obstacles to confronting them.

In order to reflect on these challenges the Forum brought together a group of experts to offer comparative perspectives rooted in their 
own national experience. We are grateful to Kai Michael Kenkel, Klaus Stüwe, Ajay K. Mehra, Edgar Mohar, Nico Steytler, Lukas Muntingh, Markus H.F. Mohler, Rainer J. Schweizer, and Richard J. Kilroy Jr for their contribution to this volume.

I would also like to thank the editors Christian Leuprecht, Mario Kölling, and Todd Hataley for their skilled creation of this important work and patience in bringing it to fruition. They worked with us to conceptualize the project, in shaping the template and editing this vast piece of research. Thanks are also due to the Giminez Abad Foundation in Zaragoza for hosting the authors' conference for this volume. I would be remiss if I didn't thank my colleagues at the Forum, Philip Gonzalez and Felix Knuepling, for managing this project at its inception, and John Light for seeing its conclusion and walking it through the publication process. Finally, thanks are due to our publisher, the University of Toronto Press, for their tireless work on this important and unique volume.

\author{
Rupak Chattopadhyay \\ President and CEO, Forum of Federations
}


This page intentionally left blank 